\title{
Resource curse: new evidence on the role of institutions
}

\begin{abstract}
This paper attempts to provide a probable answer to a longstanding resource curse puzzle; i.e., why resource-rich nations grow at a slower rate compared to less fortunate ones. Using an innovative threshold estimation technique, the empirical results reveal that there is a threshold effect in the natural resources - economic growth relationship. We find that the impact of natural resources is meaningful to economic growth only after a certain threshold point of institutional quality has been attained. The results also shed light on the fact that the nations that have low institutional quality depend heavily on natural resources while countries with high quality institutions are relatively less dependent on natural resources to generate growth.
\end{abstract}

Keyword: Economic development; Natural resource curse; Institutions 